\title{
Cystatin C is a Better Marker of Renal Dysfunction in Hypertensive Pregnancies
}

\author{
${ }^{1}$ Anjana Singh, ${ }^{2}$ Mamta Gupta, ${ }^{3}$ Rajeev Ranjan, ${ }^{4}$ Vandana Saini, ${ }^{5}$ SK Gupta
}

\section{ABSTRACT}

Background: Glomerular endotheliosis is an essential component in the pathophysiology of gestational hypertension $(\mathrm{GH})$ and preeclampsia (PE) which results in renal dysfunction. This is not always detected by routine renal function tests, such as serum creatinine, urea, and uric acid. Cystatin C, an endogenous cysteine protease inhibitor, is completely absorbed by renal tubules and has been shown to be an ideal marker of glomerular filtration rate (GFR), which needs to be evaluated in assessing renal dysfunction occurring in $\mathrm{GH}$ and $\mathrm{PE}$.

Aims: The present study is designed to evaluate serum cystatin C levels in normal pregnancy, $\mathrm{GH}$, and $\mathrm{PE}$ and compare its efficacy with traditional renal function tests.

Materials and methods: In this prospective cross-sectional study, 75 subjects enrolled, comprised of 25 subjects each of normal pregnancy, $\mathrm{GH}$, and PE. Serum cystatin $\mathrm{C}$, blood urea, serum creatinine, serum uric acid, and urinary protein/creatinine ratio were estimated in all subjects prior to delivery.

Results: All renal parameters including cystatin $\mathrm{C}$ were significantly raised in $\mathrm{GH}$ and $\mathrm{PE}$ compared with control group. However, only serum cystatin $\mathrm{C}$ level (and no other renal parameters) was significantly higher in PE group compared with $\mathrm{GH}$ group. Area under the curve for cystatin $C$ was maximum (0.917) compared with other parameters. Cystatin $\mathrm{C}$ had a higher sensitivity and specificity than other conventional markers.

Conclusion: Serum cystatin $\mathrm{C}$ is a better marker of renal dysfunction in hypertensive pregnancies.

Keywords: Cystatin C, Gestational hypertension, Hypertensive pregnancies, Preeclampsia, Renal dysfunction.

How to cite this article: Singh A, Gupta M, Ranjan R, Saini V, Gupta SK. Cystatin C is a Better Marker of Renal Dysfunction in Hypertensive Pregnancies. Indian J Med Biochem 2016; 20(1):21-27.

Source of support: The study was done by institutional funding. Conflict of interest: None.

\footnotetext{
${ }^{1}$ DNB Student, ${ }^{2,3}$ Head, ${ }^{4}$ Senior Specialist, ${ }^{5}$ Director Professor

1,2,4 Department of Obstetrics and Gynaecology, Hindu Rao Hospital \& Associated North Delhi Municipal Corporation Medical College, Delhi, India

${ }^{3}$ Department of Biochemistry, Hindu Rao Hospital \& Associated North Delhi Municipal Corporation Medical College, Delhi, India

${ }^{5}$ Department of Biochemistry, Maulana Azad Medical College Delhi, India
}

Corresponding Author: Mamta Gupta, Head, Department of Obstetrics and Gynaecology, Hindu Rao Hospital \& Associated North Delhi Municipal Corporation Medical College, Delhi, India Phone: +919868611385, e-mail: write2mamta55@gmail.com

\section{INTRODUCTION}

Gestational hypertension (GH) and preeclampsia (PE) are pregnancy-specific hypertensive disorders. Both carry high maternal and fetal risk. Termination of pregnancy is the only definitive cure for these conditions.

In normal pregnancy, glomerular filtration rate (GFR) is physiologically increased by $50 \% .{ }^{1}$ But glomerular endotheliosis, seen in both $\mathrm{GH}$ and $\mathrm{PE}$, leads to decrease in GFR than in normal pregnancy. ${ }^{2}$ This decreased GFR, can eventually lead to renal failure in PE. Kidney function therefore needs to be closely monitored in women with $\mathrm{GH}$ and PE so that timely termination of pregnancy for a better fetomaternal outcome can be done.

The traditional markers of renal function followed widely, i.e., serum creatinine, urea, and uric acid levels, have several limitations.

Serum creatinine, though most widely used, is significantly influenced by body weight, physical activity, and diet. ${ }^{3}$ After filtration by the glomerulus, it is reabsorbed and then secreted by tubules. The secretion increases with the increase in serum creatinine. Initially thus, serum creatinine does not rise and remains normal till about $50 \%$ of renal function is lost. Thus, there is a creatinine blind area where mild-to-moderate decrease in GFR is not reflected in serum creatinine levels.

Uric acid is also filtered, reabsorbed, and secreted by the kidney. Its levels are also influenced by diet and alcohol consumption. Increased tissue breakdown, hypovolemia, and acidosis seen in hypertensive pregnancies also increase uric acid level. Thus, increased uric acid levels may not necessarily indicate renal dysfunction.

Blood urea, the major nitrogen-containing catabolic product of proteins in humans, is widely regarded as a test of renal function but is affected by protein intake, liver metabolic capacity, renal perfusion, and hydration.

Serum cystatin $C$ is a new emerging endogenous marker of renal function. It is produced by all nucleated cells and is a cysteine protease inhibitor. Its blood levels are not dependent on age, sex, diet, muscle mass, or inflammatory process. Unlike creatinine, it is almost exclusively eliminated from the circulation by glomerulus. Its serum concentration reflects GFR more closely than creatinine. Unlike serum creatinine, there is no cystatin $\mathrm{C}$ blind area because it is not secreted by tubules. It is 
completely reabsorbed and metabolized by tubular cells. Studies have shown superior diagnostic sensitivity of serum cystatin C levels for the detection of mildly impaired GFR. ${ }^{4,5}$

Serum cystatin $C$ has been studied as a useful marker for assessment of renal dysfunction, in acute kidney injury, ${ }^{6}$ chronic kidney disease, ${ }^{7}$ renal transplantation, ${ }^{8}$ diabetes, ${ }^{9}$ prediabetes, ${ }^{10}$ etc., and has been considered better than other traditional markers of renal dysfunction.

Not much work has been done on serum cystatin $C$ as a marker of renal dysfunction in hypertensive disorders of pregnancy, hence, the need for its evaluation.

\section{AIMS AND OBJECTIVES}

To evaluate serum cystatin $\mathrm{C}$ levels as a marker of renal dysfunction in women with normal pregnancy, GH, and PE and compare it with serum creatinine, blood urea, and serum uric acid.

\section{MATERIALS AND METHODS}

This cross-sectional observational study was carried out on in a tertiary care urban hospital, from May 2012 to April 2014. Ethical clearance was obtained from the institutional ethical committee. Written consent was taken from all the women enrolled for the study. The study subjects comprised of three groups of 25 each - group A with normal pregnancy, group B with $\mathrm{GH}$, and group $\mathrm{C}$ with PE.

Gestational hypertension was defined as blood pressure (BP) more than 140/90 mm Hg occurring after 20 weeks of pregnancy on two occasions 6 hours apart without significant proteinuria. Preeclampsia was defined as BP more than 140/90 mm Hg occurring after 20 weeks on two occasions 6 hours apart with significant proteinuria, detected by spot urine protein/creatinine ratio more than $0.3 .^{11}$

Patients with preexisting hypertension, chronic hypertension with superimposed PE, diabetes, renal disease, multiple pregnancy, thyroid disease, and eclampsia were excluded from the study.

Fasting venous blood sample was drawn and serum was separated for estimation of cystatin $C$ and other renal parameters. Spot urine sample was also collected for urinary estimation of protein/creatinine ratio. All samples for analysis were taken at term, on admission to labor ward, or just prior to induction of labor.

Serum cystatin $\mathrm{C}$ and urinary albumin (for urinary protein/creatinine ratio) were estimated by immunoturbidimetric assay using Agape's and Erba transasia kits respectively. Serum creatinine, urea, and uric acid and urine creatinine (for urinary protein/creatinine ratio) were assayed by standard enzymatic methods. All assays were carried out on fully automatic Erba XL 300 autoanalyzer.

All the patients were followed till delivery and the relevant details like demographic features and results of renal function tests were recorded in a predesigned proforma. The results were statistically analyzed.

\section{RESULTS}

The general demographic profile is shown in Table 1. Except for parity, all the demographic parameters were comparable in the three groups.

Analysis of renal functions revealed that all renal parameters were raised in group C (Table 2); however, only serum cystatin $C$ levels were significantly raised in group $C$ than in group B, not seen with other parameters.

Since serum cystatin $C$ was found to discriminate between groups B and C, its correlation with other renal parameters was studied in all hypertensive pregnant women $(n=50$, groups $B+C)$. Cystatin $C$ showed a positive corelation with all the other renal parameters. Urinary proteins had the best correlation with cystatin C followed by urinary protein:creatinine ratio (Table 3).

Receiver operating characteristic (ROC) analysis and area under the curve (AUC) showed that cystatin C had

Table 1: Demographic details of study subjects

\begin{tabular}{lllll}
\hline & $\begin{array}{l}\text { Normal pregnancy } \\
\text { group A } \\
n=25\end{array}$ & $\begin{array}{l}\text { GH } \\
\text { group } B\end{array}$ & $\begin{array}{l}\text { PE } \\
\text { group C } \\
n=25\end{array}$ & $\begin{array}{l}\text { Statistical significance } \\
p \text {-value }\end{array}$ \\
\hline Age (mean \pm SD) & $25.6 \pm 2.81$ years & $25.12 \pm 2.55$ years & $25.2 \pm 3.2$ years & 0.81 \\
Parity - primi & $24 \%$ & $44 \%$ & $64 \%$ & $0.01 \mathrm{~S}$ \\
P1 & $52 \%$ & $32 \%$ & $24 \%$ & $12 \%$ \\
P2 & $16 \%$ & $25 \%$ & $0 \%$ & 0.099 \\
P3 and more & $8 \%$ & $4 \%$ & $260.36 \pm 33.87$ & NS \\
POG (mean \pm SD) days & $271.44 \pm 7.62$ & $266.84 \pm 11.39$ & & 0.704 \\
History of high BP in prev. pregnancy & $16 \%$ & & $24 \%$ & $\mathrm{NS}$ \\
Family history of hypertension & $12 \%$ & $16 \%$ & & $\mathrm{NS}$ \\
\hline
\end{tabular}

S: Significant; NS: Not significant 
Cystatin C is a Better Marker of Renal Dysfunction in Hypertensive Pregnancies

Table 2: Renal parameters in the three groups

\begin{tabular}{|c|c|c|c|c|c|c|}
\hline \multirow[b]{2}{*}{ Renal parameter } & \multicolumn{3}{|c|}{ Mean $\pm S D$} & \multicolumn{3}{|c|}{$p$-value } \\
\hline & Normal preg. group $A$ & GH group $B$ & PE group $C$ & $A / B$ group & A/C group & $B / C$ group \\
\hline Uric acid (mg/dL) & $3.86 \pm 1.25$ & $5.15 \pm 1.05$ & $5.6 \pm 1.38$ & 0.001 & 0.000 & 0.418 \\
\hline Creatinine (mg/dL) & $0.728 \pm 0.084$ & $0.828 \pm 0.067$ & $0.86 \pm 0.173$ & 0.010 & 0.001 & 0.605 \\
\hline Urea (mg/dL) & $19.48 \pm 3.12$ & $23.52 \pm 3.4$ & $25.64 \pm 7.46$ & 0.017 & 0.000 & 0.309 \\
\hline Cystatin C (mg/L) & $0.962 \pm 0.232$ & $1.261 \pm 0.28$ & $1.62 \pm 0.328$ & 0.001 & 0.000 & 0.000 \\
\hline
\end{tabular}

${ }^{*} p$ value determined by one-way ANOVA followed by Tukey honest significant difference test; <0.05 significant

Table 3: Correlation of serum cystatin $C$ and other renal parameters in hypertensive pregnant women $(n=50)$

\begin{tabular}{llllll}
\hline $\begin{array}{l}\text { With } \\
\text { cystatin C }\end{array}$ & Urea & $\begin{array}{l}\text { Uric } \\
\text { acid }\end{array}$ & Creatinine & $\begin{array}{l}\text { Urinary } \\
\text { protein }\end{array}$ & $\begin{array}{l}\text { Urine protein/ } \\
\text { creatinine ratio }\end{array}$ \\
\hline $\begin{array}{l}\text { Correlation } \\
\text { r-value }\end{array}$ & 0.291 & 0.325 & 0.287 & 0.657 & 0.630 \\
p-value & 0.040 & 0.021 & 0.043 & 0.000 & 0.000 \\
\hline
\end{tabular}

$<0.05$ significant

Table 4: Analysis and area under the curve for cystatin $C$ and other renal parameters

\begin{tabular}{|c|c|c|c|c|c|}
\hline \multirow[b]{2}{*}{$\begin{array}{l}\text { Test result } \\
\text { variable(s) }\end{array}$} & \multirow[b]{2}{*}{$A \cup C$} & \multirow[b]{2}{*}{$\begin{array}{l}\text { Std. } \\
\text { error }\end{array}$} & \multirow[b]{2}{*}{$\begin{array}{l}\text { Asymptotic } \\
\text { sig. }\end{array}$} & \multicolumn{2}{|c|}{$\begin{array}{c}95 \% \text { confidence } \\
\text { interval }\end{array}$} \\
\hline & & & & $\begin{array}{l}\text { Lower } \\
\text { bound }\end{array}$ & $\begin{array}{l}\text { Upper } \\
\text { bound }\end{array}$ \\
\hline Urea & 0.831 & 0.053 & 0.000 & 0.727 & 0.936 \\
\hline Uric acid & 0.808 & 0.056 & 0.000 & 0.698 & 0.919 \\
\hline Serum creatinine & 0.796 & 0.055 & 0.000 & 0.688 & 0.903 \\
\hline Serum cystatin $C$ & 0.917 & 0.041 & 0.000 & 0.837 & 0.997 \\
\hline
\end{tabular}

$<0.05$ significant

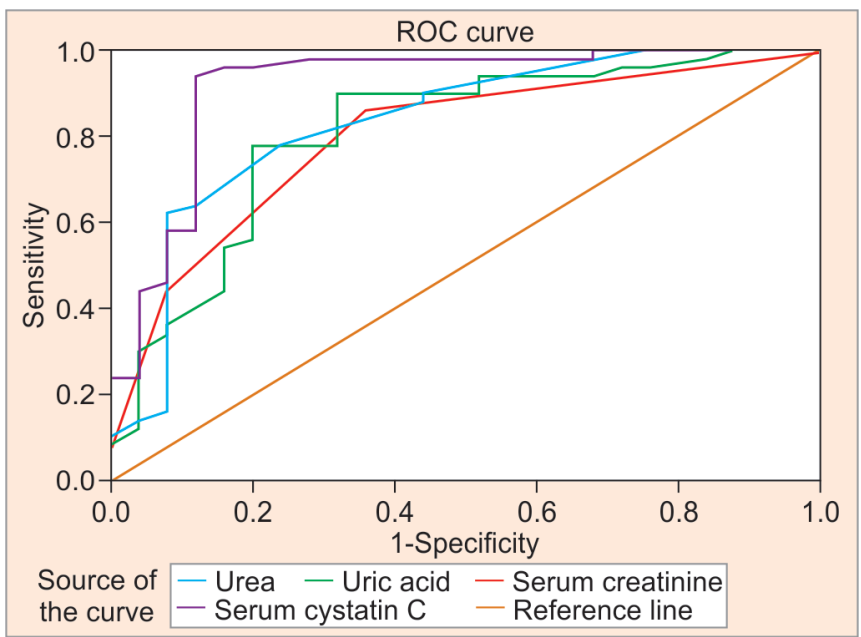

Graph 1: Receiver operating characteristic curve for cystatin C and other renal parameters

a better performance than other markers (Table 4 and Graph 1). It was observed that cystatin $C$ had maximum sensitivity of $94 \%$ and specificity of $88 \%$ (Table 5).

Maternal outcome in the three groups was evaluated in terms of mode of delivery (Table 6 and Graph 2) and postpartum hemorrhage (PPH; Table 7).

There was no PPH in control group A; however, in hypertensive groups $\mathrm{B}$ and $\mathrm{C}$, six patients had $\mathrm{PPH}$. Though mean uric acid in hypertensive pregnant women with average blood loss compared with women who had
Table 5: Sensitivity and specificity of cystatin $C$ and other renal parameters

\begin{tabular}{llll}
\hline Variable & Cut-off value & Sensitivity & Specificity \\
\hline Urea $(\mathrm{mg} / \mathrm{dL})$ & 21 & $78 \%$ & $76 \%$ \\
Uric acid $(\mathrm{mg} / \mathrm{dL})$ & 4.1 & $88 \%$ & $68 \%$ \\
S. Creatinine $(\mathrm{mg} / \mathrm{dL})$ & 0.75 & $86 \%$ & $64 \%$ \\
S. Cystatin C (mg/L) & 1.055 & $94 \%$ & $88 \%$ \\
\hline
\end{tabular}

$<0.05$ significant

Table 6: Mode of delivery in different groups

\begin{tabular}{lllll}
\hline Mode of delivery & Group A & Group B & Group C & Total \\
\hline 1 Spontaneous, vaginal & 19 & 11 & 2 & 32 \\
$\begin{array}{l}\text { delivery } \\
2 \begin{array}{l}\text { Induction of labor, } \\
\text { vaginal delivery }\end{array}\end{array}$ & $2^{*}$ & 5 & 11 & 18 \\
$3 \begin{array}{l}\text { LSCS for } \\
\text { nonhypertension } \\
\text { indication** }\end{array}$ & 4 & 5 & 4 & 13 \\
$4 \begin{array}{l}\text { LSCS for hypertension- } \\
\text { related indication }\end{array}$ & 0 & 4 & 8 & 12 \\
\hline
\end{tabular}

In group A, * patients had induction for postmaturity; **Includes patients who had lower segment cesarean section (LSCS) for nonhypertension indication, i.e., transverse lie, breech presentation, placenta previa, cephalopelvic disproportion, etc; \#Includes patients who had LSCS for hypertension-related indication, i.e., failed induction for hypertension, uncontrolled $\mathrm{BP}$ on multiple antihypertensive drugs, impending eclampsia with poor Bishop score, abruptio placentae, fetal distress with IUGR

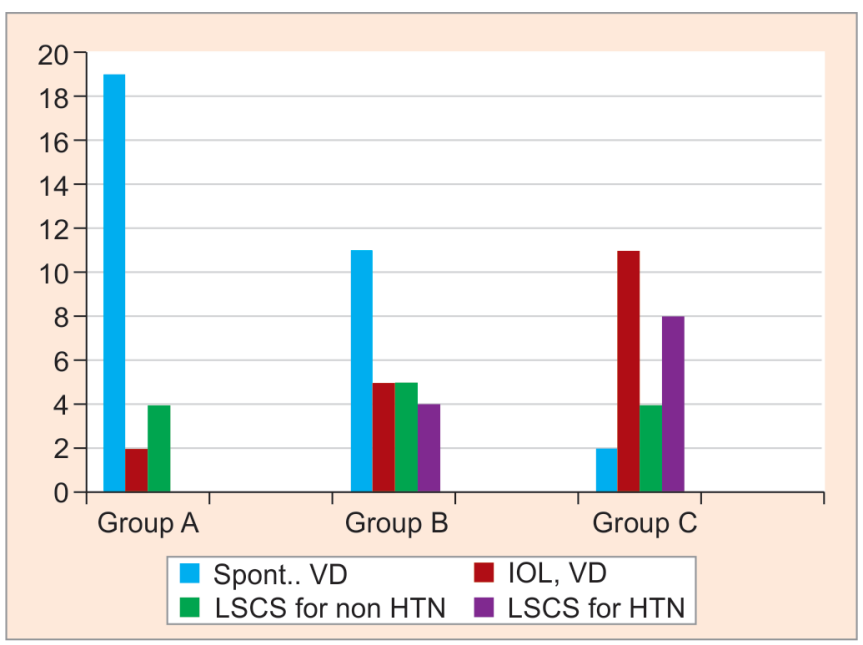

Graph 2: Mode of delivery in the three groups. IOL: Induction of labor; LSCS: Lower segment cesarean section; HTN: Hypertension 
Table 7: Renal parameters in hypertensive pregnant women with PPH $(n=50)$

\begin{tabular}{|c|c|c|c|}
\hline \multirow[b]{2}{*}{ Renal parameter } & \multicolumn{2}{|c|}{$\begin{array}{l}\text { Blood loss in hypertensive group } \\
\text { during delivery }\end{array}$} & \multirow[b]{2}{*}{$p$-value } \\
\hline & $\begin{array}{l}\text { Average loss } \\
(n=44)\end{array}$ & $P P H(n=6)$ & \\
\hline Mean urea $(\mathrm{mg} / \mathrm{dL})$ & $24.4773 \pm 6.02510$ & $25.33 \pm 4.84424$ & 0.741 \\
\hline $\begin{array}{l}\text { Mean uric acid } \\
(\mathrm{mg} / \mathrm{dL})\end{array}$ & $5.2318 \pm 1.13931$ & $6.4500 \pm 1.50033$ & 0.022 \\
\hline $\begin{array}{l}\text { Mean creatinine } \\
(\mathrm{mg} / \mathrm{dL})\end{array}$ & $0.8341 \pm 0.13108$ & $0.9167 \pm 0.11690$ & 0.150 \\
\hline $\begin{array}{l}\text { Mean cystatin C } \\
(\mathrm{mg} / \mathrm{L})\end{array}$ & $1.3936 \pm 0.29479$ & $1.7900 \pm 0.55516$ & 0.008 \\
\hline
\end{tabular}

Table 8: Fetal growth and other renal parameter in control group $A(n=25)$

\begin{tabular}{llll}
\hline & \multicolumn{3}{c}{ Growth of fetus } \\
\cline { 2 - 3 } & Normal $(n=22)$ & IUGR $(n=3)$ & $p$-value \\
\hline Mean urea $(\mathrm{mg} / \mathrm{dL})$ & 19.818 & 17.000 & 0.146 \\
Mean uric acid $(\mathrm{mg} / \mathrm{dL})$ & 3.831 & 4.100 & 0.737 \\
Mean creatinine $(\mathrm{mg} / \mathrm{dL})$ & 0.736 & 0.666 & 0.184 \\
Mean cystatin C $(\mathrm{mg} / \mathrm{L})$ & 0.980 & 0.833 & 0.314 \\
\hline
\end{tabular}

Table 9: Fetal growth and renal parameter in hypertensive women $(n=50)$

\begin{tabular}{lllll}
\hline & \multicolumn{3}{c}{ Growth of fetus } & \\
\cline { 2 - 4 } & $\begin{array}{l}\text { Normal } \\
(n=26)\end{array}$ & $\begin{array}{l}\text { IUGR } \\
(n=22)\end{array}$ & $\begin{array}{l}\text { IUD } \\
(n=2)\end{array}$ & $p$-value \\
\hline Mean urea $(\mathrm{mg} / \mathrm{dL})$ & 22.654 & 26.727 & 26.000 & 0.05 \\
Mean uric acid $(\mathrm{mg} / \mathrm{dL})$ & 5.154 & 5.500 & 6.950 & 0.115 \\
Mean creatinine $(\mathrm{mg} / \mathrm{dL})$ & 0.789 & 0.914 & 0.800 & 0.002 \\
Mean cystatin C $(\mathrm{mg} / \mathrm{L})$ & 1.3127 & 1.5582 & 1.8250 & 0.013 \\
\hline
\end{tabular}

Table 10: Mean Apgar scores and birth weight in the three groups

\begin{tabular}{llll}
\hline & Group $A$ & Group B & Group C \\
& $n=25$ & $n=25$ & $n=25$ \\
\hline Mean Apgar \pm SD at 1 min & $8.84 \pm 0.624$ & $8.64 \pm 0.569$ & $7.6 \pm 2.38$ \\
Mean birth weight, $\mathrm{kg} \pm \mathrm{SD}$ & $2.75 \pm 0.353$ & $2.5 \pm 0.387$ & $2.3 \pm 0.72$ \\
\hline
\end{tabular}

$\mathrm{PPH}$ was statistically significant (p-value 0.022 , $\mathrm{t}$-test,) mean cystatin $\mathrm{C}$ in PPH and non-PPH groups was statistically highly significant (p-value 0.008, t-test) (Table 7).

Fetal outcome was evaluated in terms of fetal growth (Tables 8 and 9), fetal weight, and Apgar score (Table 10).

In the control group A, only three babies had intrauterine growth restriction (IUGR); none had intrauterine fetal death (IUD). The renal parameters in women with normal growth and IUGR were comparable (Table 8). However, in the hypertensive group, mean creatinine and cystatin $\mathrm{C}$ were significantly different in women having normal fetal growth, IUGR, and IUD (Table 9).

The pattern of increase/decrease in various renal parameters was analyzed in hypertensive women having normal growth, IUGR, and IUD (Graphs 3 to 6). It was

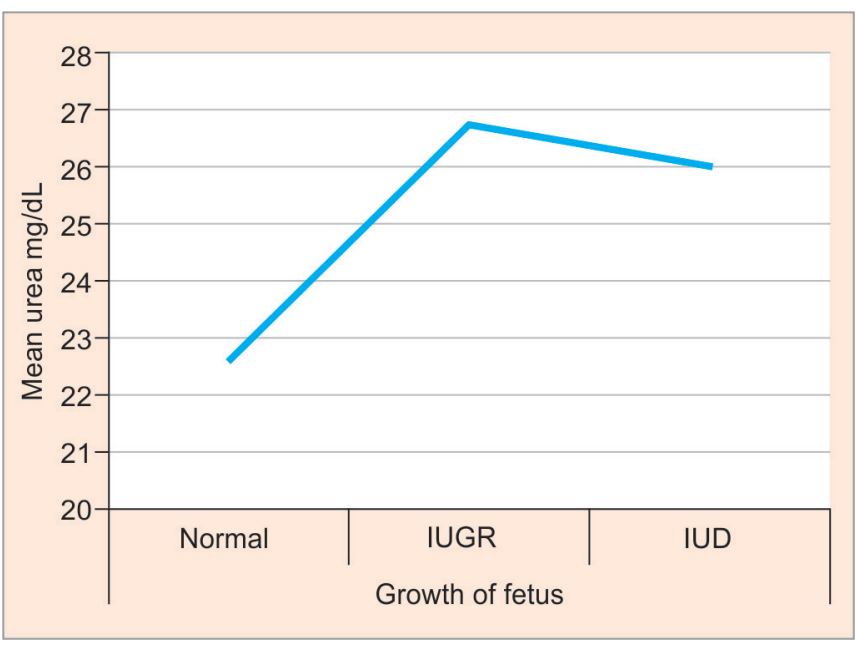

Graph 3: Mean urea and fetal growth

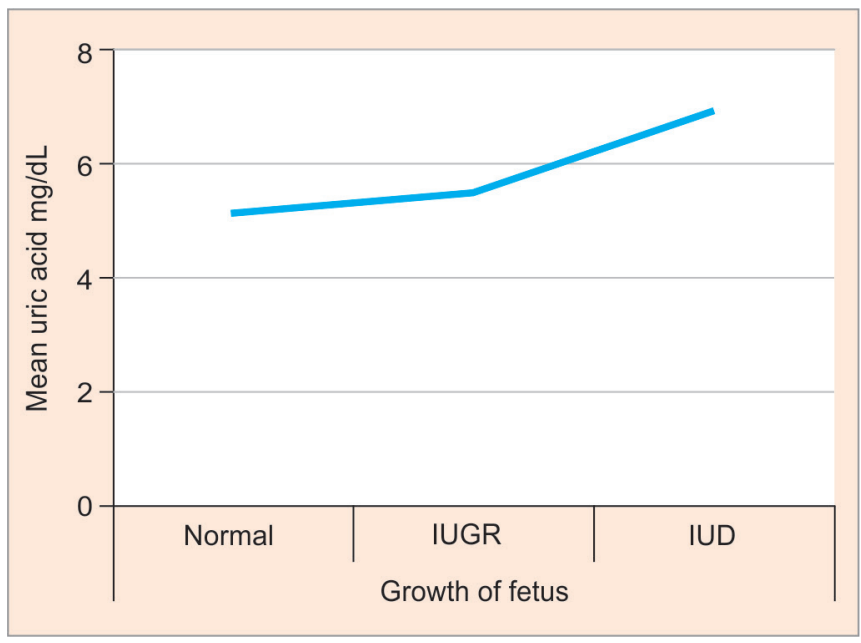

Graph 4: Mean uric acid and fetal growth

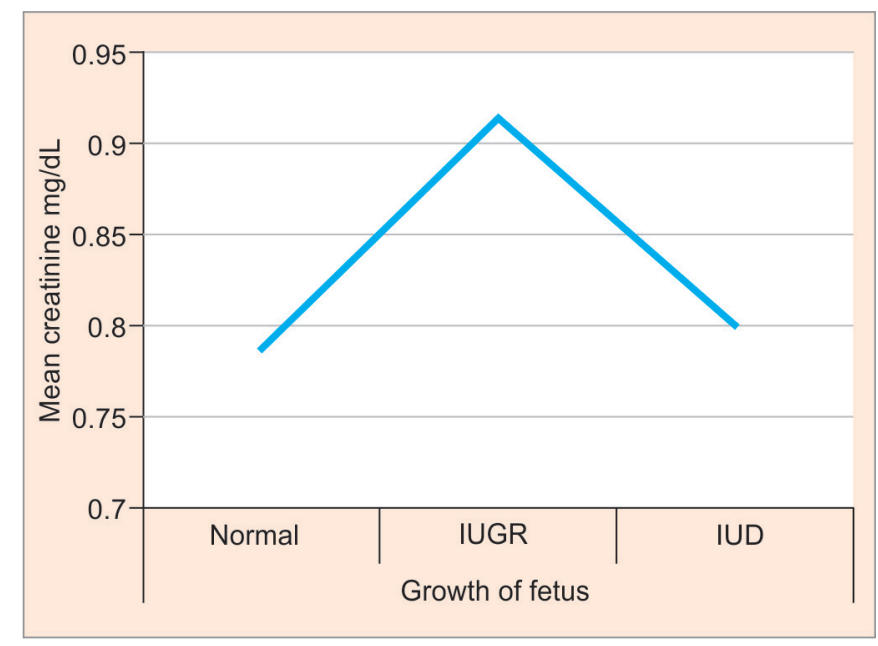

Graph 5: Mean creatinine and growth of fetus

observed that mean urea levels increased in women having normal fetal growth and IUGR but remained stationary or minimally decreased when IUD occurred (Graph 3). Some increase in mean uric acid occurred in women with normal growth and when IUGR occurred; 


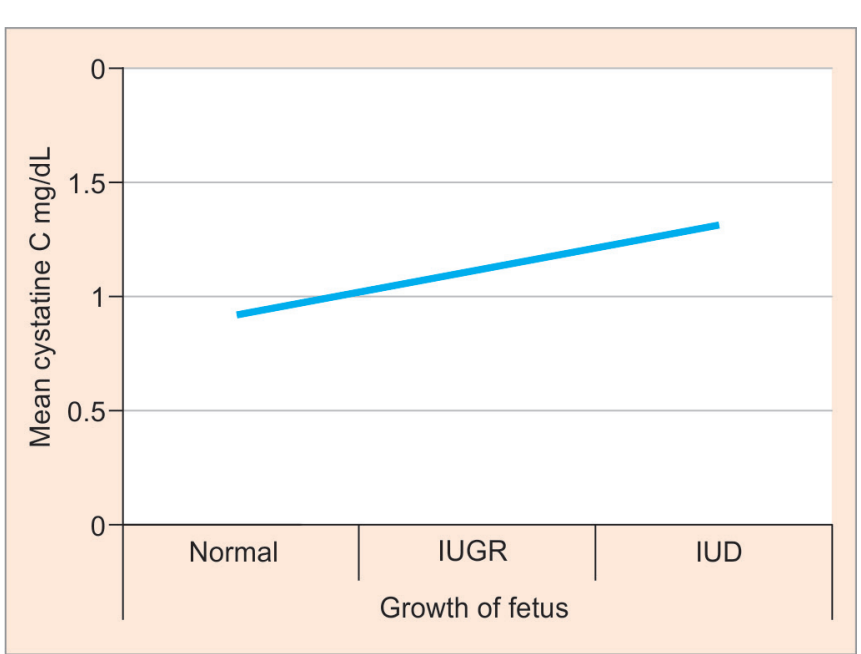

Graph 6: Mean cystatin C and growth of fetus

Table 11: Correlation of Apgar score and birth weight with renal parameters $(n=50)$

\begin{tabular}{llcccc}
\hline & & Urea & Uric acid & Creatinine & Cystatin C \\
\hline Apgar at & p-value & 0.084 & 0.005 & 0.016 & 0.002 \\
1 min & Correlation & -0.247 & $-0.393^{* *}$ & $-0.341^{*}$ & $-0.421^{* *}$ \\
& r-value & & & & \\
Baby & p-value & 0.022 & 0.060 & 0.000 & 0.012 \\
weight at & Correlation & $-0.324^{*}$ & -0.268 & $-0.507^{* *}$ & $-0.353^{*}$ \\
birth & r-value & & & & \\
\hline
\end{tabular}

the rise of uric acid was substantial in women who had IUD compared with IUGR (Graph 4). Regarding serum creatinine, it was observed that as IUGR developed from normal growth, creatinine increased substantially but again decreased when IUD occurred from IUGR (Graph 5). Cystatin $\mathrm{C}$, however, increased in a linear pattern in all stages of fetal growth (Graph 6); rising levels therefore reflect directly fetal outcome in terms of fetal growth.

A negative correlation between uric acid, creatinine, and cystatin $\mathrm{C}$ with Apgar score at 1 minute in hypertensive pregnant women was seen, but cystatin $C$ had the maximum negative correlation with 1 minute Apgar score. In regard to birth weight, a stronger negative correlation with serum creatinine was observed than with cystatin C (Table 11).

\section{DISCUSSION}

Altered renal function is an essential part of pathophysiology of hypertensive disorders of pregnancy due to the characteristic lesion "glomerular endotheliosis" and hemodynamic changes causing decreased GFR, renal dysfunction, and even renal failure. Hence, close monitoring is essential to ascertain the optimal time for delivery in fetomaternal interest.

In search of an ideal renal marker in PE, which may overcome the limitations of the conventional markers, the present study on cystatin $C$ as a marker of renal function was undertaken.

The general demographic profile of study subjects is shown in Table 1. Appropriate statistical tests were applied to all the demographic parameters. Mean age was comparable in all the three groups [p-value 0.81, analysis of variance (ANOVA) test]. Most patients in PE and $\mathrm{GH}$ group were primiparas, which was significant (group A vs C p-value 0.01, Fisher exact chi-square test). Mean period of gestation (POG) was less in GH (271.44 days) and PE (260.36 days) groups than in the control group (271.44 days), though not statistically significant ( $p>0.05$, ANOVA test). History of hypertension in previous pregnancies and family history (sisters, parents/ grandparents of women) of hypertension were more common in PE group than in GH or normal pregnancy, though not statistically significant (p-value 1, ANOVA test). These findings confirm the association of known risk factors for the disease, i.e., primiparity, past history of hypertension, and family history.

It was observed in our study that serum levels of all the renal markers cystatin $C$, creatinine, urea, and uric acid were significantly raised in $\mathrm{GH}$ and $\mathrm{PE}$ groups compared with the control group ( $\mathrm{p}<0.01$, ANOVA and Tukey test) (Table 2). The raised levels of renal parameters were significant in PE group and GH group compared with control group, signifying some degree of renal dysfunction associated with GH and PE women.

Further, it was observed in our study that only serum cystatin C levels were significantly higher in PE group compared with GH group (p-value 0.00), indicating that it may be an early marker of PE as it is found to be raised significantly even at a nonproteinuric stage of the disease (GH). This finding of our study is significant and is clinically useful in closely monitoring those GH women who have higher cystatin C levels and are likely to develop PE. Hence, cystatin C can be helpful in prognostication of hypertensive pregnant women as $\mathrm{GH}$ has a relatively benign course than PE.

Several studies have reported higher cystatin $C$ levels in PE patients than normal pregnant women. It has been reported as a marker of GFR in hypertensive pregnancies, glomeruloendotheliosis, and an early marker of PE. A large number of studies have unequivocally shown serum cystatin C levels a better marker of GFR in nonpregnant healthy women as well as normal pregnant women and also in PE women ${ }^{12-15}$ than serum creatinine levels.

Cystatin C levels have been estimated in PE subjects in many studies and have been found to be superior. ${ }^{4,12,13,16}$ A meta-analysis by Dharnidharka et $\mathrm{al}^{17}$ in 46 subjects has found serum cystatin $C$ to be clearly superior to serum creatinine as a marker of GFR measured by correlation 
or mean ROC-AUC plot. We have come across only one study by Padma et $\mathrm{al}^{18}$ who have estimated cystatin $\mathrm{C}$ in women with GH as well as PE in which higher cystatin C levels in GH and PE than in normal pregnant controls has been reported. However, in this study, ${ }^{18}$ serum creatinine has been reported to be a better indicator of renal function. One possible reason could be that they have used Jaffe's reagent-based kinetic assay than the enzymatic methods used in our study, which has been shown to be more accurate with reference method. ${ }^{19}$

In our study, we had estimated urinary protein/ creatinine ratio to select the patients for groups B or C (cut-off level being 0.3 ) and it was not the primary aim to correlate cystatin $C$ levels with either urinary protein or urinary protein/creatinine ratio. However, we did find a strong positive correlation of cystatin $C$ with urinary protein and uinary protein/creatinine ratio (r-value 0.657 and 0.630 ) respectively, with $p$-value 0.00 (Table 3). Proteinuria itself is the most important marker of glomerular function, supporting our view regarding cystatin $\mathrm{C}$ as a marker of renal function in PE and GH where glomeruloendotheliosis is considered to be an essential pathophysiology. This secondary outcome of our study further strengthens the emerging view that increased and rising serum cystatin C levels in women with GH may be an indicator of impending PE, even when there is no proteinuria or at a nonproteinuric stage of the disease. Extrapolated, this observation might be helpful in predicting the development of PE in women with GH and also superimposed PE in a patient having chronic hypertension. Taken together, these are novel findings of our study.

Receiver operating characteristic analysis of the various renal markers in our study revealed maximum AUC for cystatin C (0.917) followed by urea (0.831), uric acid (0.808), and creatinine (0.796), suggesting maximum diagnostic performance of cystatin $\mathrm{C}$ to detect renal dysfunction in hypertensive pregnant women (Table 4 and Graph 1). The sensitivity (94\%) and specificity (88\%) of cystatin $C$ were maximum. Thus, cystatin $C$ appears to pick up more women with renal dysfunction in PE and $\mathrm{GH}$, also at an earlier nonproteinuric stage as indicated in Table 2. Elegwany et $\mathrm{al}^{20}$ have shown a sensitivity of $72.5 \%$ and specificity of $100 \%$ for cystatin C (Table 5).

In our study, it was observed that cystatin $C$ had a good correlation with fetomaternal outcome. Apgar score at 1 minute had a good correlation with cystatin $C$ (r-value -0.421), though birth weight correlated better with serum creatinine. We had an important and unique observation in our study regarding fetal growth, which we have not come across in any study in the literature with our best efforts. A linear association with cystatin C
(Graph 6) and rising cystatin C levels were observed, reflecting deteriorating fetal growth from normal growth to IUGR and IUD. This is in contrast to other renal parameters where fetal deterioration due to hypertensive placental pathology is not reflected always by rising renal parameters (Graphs 3 to 5).

Maternal outcome in terms of PPH also had a good correlation with cystatin $C$. We have not come across any other study to the best of our efforts where fetomaternal outcome has been correlated with serum cystatin C levels in pregnant hypertensive women.

\section{CONCLUSION}

Our study shows serum cystatin $C$ to be a better marker compared with the conventional tests, in detecting renal dysfunction in women with GH and PE. It is clinically useful in closely monitoring those GH women who have higher cystatin $C$ levels and are likely to develop PE. Thus, it can be used for prognostication of hypertensive pregnancies. Its strong positive correlation with urinary protein and protein/creatinine ratio might be helpful in predicting development of PE in women with $\mathrm{GH}$ and also superimposed PE in a patient having chronic hypertension. It has been found to correlate well with fetomaternal outcomes in hypertensive disorders of pregnancy.

It was demonstrated that serum cystatin $C$ had a better sensitivity and specificity than the traditional markers of renal dysfunction. Estimation of cystatin $C$ should therefore be included in routine work-up of PE and GH patients.

\section{REFERENCES}

1. Cheung KL, Lafayette RA. Renal physiology of pregnancy. Adv Chronic Kidney Dis 2013 May;20(3):209-214.

2. Stillman IE, Karumanchi SA. The glomerular injury of preeclampsia. J Am Soc Nephrol 2007 Aug;18(8):2281-2284.

3. Samra M, Abcar AC. False estimates of elevated creatinine. Perm J 2012 Spring;16(2):51-52.

4. Strevens H, Wide-Swensson D, Grubb A. Serum cystatin C is a better marker for preeclampsia than serum creatinine or serum urate. Scand J Clin Lab Invest 2001;61(7):575-580.

5. Wei L, YeX, Pei X, Wu J, Zhao W. Reference intervals for serum cystatin $C$ and factors influencing cystatin $C$ levels other than renal function in the elderly. PLoS One 2014 Jan;9(1):e86066.

6. Murty MS, Sharma UK, Pandey VB, Kankare SB. Serum cystatin $\mathrm{C}$ as a marker of renal function in detection of early acute kidney injury. Indian J Nephrol 2013 May;23(3):180-183.

7. Peralta CA, Katz R, Sarnak MJ, lx J, Fried LF, De Boer I, Palmas W, Siscovick D, Levey AS, Shlipak MG. Cystatin C identifies chronic kidney disease patients at higher risk for complications. J Am Soc Nephrol 2011 Jan;22(1):147-155.

8. Ayub S, Zafar MN, Aziz T, Iqbal T, Khan S, Rizvi SA. Evaluation of renal function by cystatin $\mathrm{C}$ in renal transplant recipients. Exp Clin Transplant 2014 Feb;12(1):37-40. 
9. Jeon YL, Kim MH, Lee WI, Kang SY. Cystatin C as an early marker of diabetic nephropathy in patients with type 2 diabetes. Clin Lab 2013;59(11-12):1221-1229.

10. Sabanayagam C, Wong TY, Xiao J, Shankar A. Serum cystatin $\mathrm{C}$ and prediabetes in non-obese US adults. Eur J Epidemiol 2013 Apr;28(4):311-316.

11. Uzan J, Carbonnel M, Piconne O, Asmar R, Ayoubi JM. Preeclampsia: pathophysiology, diagnosis, and management. Vasc Health Risk Manag 2011;7:467-474.

12. Sharma S, Ranjan RK, Gupta M, Singh A, Gupta R, Pant L, Singh S. Serum cystatin $C$ with conventional renal tests: a study in patients with pre-eclampsia. Ann Pathol Lab Med 2014;1(2):A6-A9.

13. Novakov Mikic A, Cabarkapa V, Nikolic A, Maric D, Brkic S, Mitic G, Ristic M, Stosic Z. Cystatin C in pre-eclampsia. J Matern Fetal Neonatal Med 2012 Jul;25(7):961-965.

14. Strevens H, Wide-Swensson D, Torffvit O, Grubb A. Serum cystatin $\mathrm{C}$ for assessment of glomerular filtration rate in pregnant and non pregnant women. Indications of altered filtration process in pregnancy. Scand J Clin Lab Invest 2002;62(2):141-147.
15. Dhupper V, Ghahlaut VS, Kulshrestha MR, Bhadra J, Yadav U, Mahor DS. Evaluation of cystatin C as a marker of estimated glomerular filtration rate (eGFR) in different stages of chronic kidney disease (CKD). Sch Acad J Biosci 2015;3(4):328-334.

16. Salma M, Omar FE. Evaluation of serum cystatin $C$ compared with creatinine: a study in patients with pre-eclampsia. Int J Pharmacol Res 2015;5(11):273-275.

17. Dharnidharka VR, Kwon C, Stevens G. Serum cystatin C is superior to serum creatinine as a marker of kidney function: a meta-analysis. Am J Kidney Dis 2002 Aug;40(2):221-226.

18. Padma Y, Aparna VB, Kalpana B, Ritika V, Sudhakar PR. Renal markers in normal and hypertensive disorders of pregnancy in Indian women: a pilot study. Int J Reprod Contracept Obstet Gynecol 2013;2(4):514-520.

19. Peake M, Whiting M. Measurement of serum creatinine current status and future goals. Clin Biochem Rev 2006 Nov;27(4):173-184.

20. Elegwany AS, Eidayem TMA, Karkour TAZ, Elmoneem ELdeghedy AA, Morsy HR. The application of serum cystatin $C$ in estimating renal function in women with severe preeclamptic toxemia. Prog Obstet Ginecol 2015. Available from: http://dx.DOI.org/10.1016/j.pog.2015.06.005 